
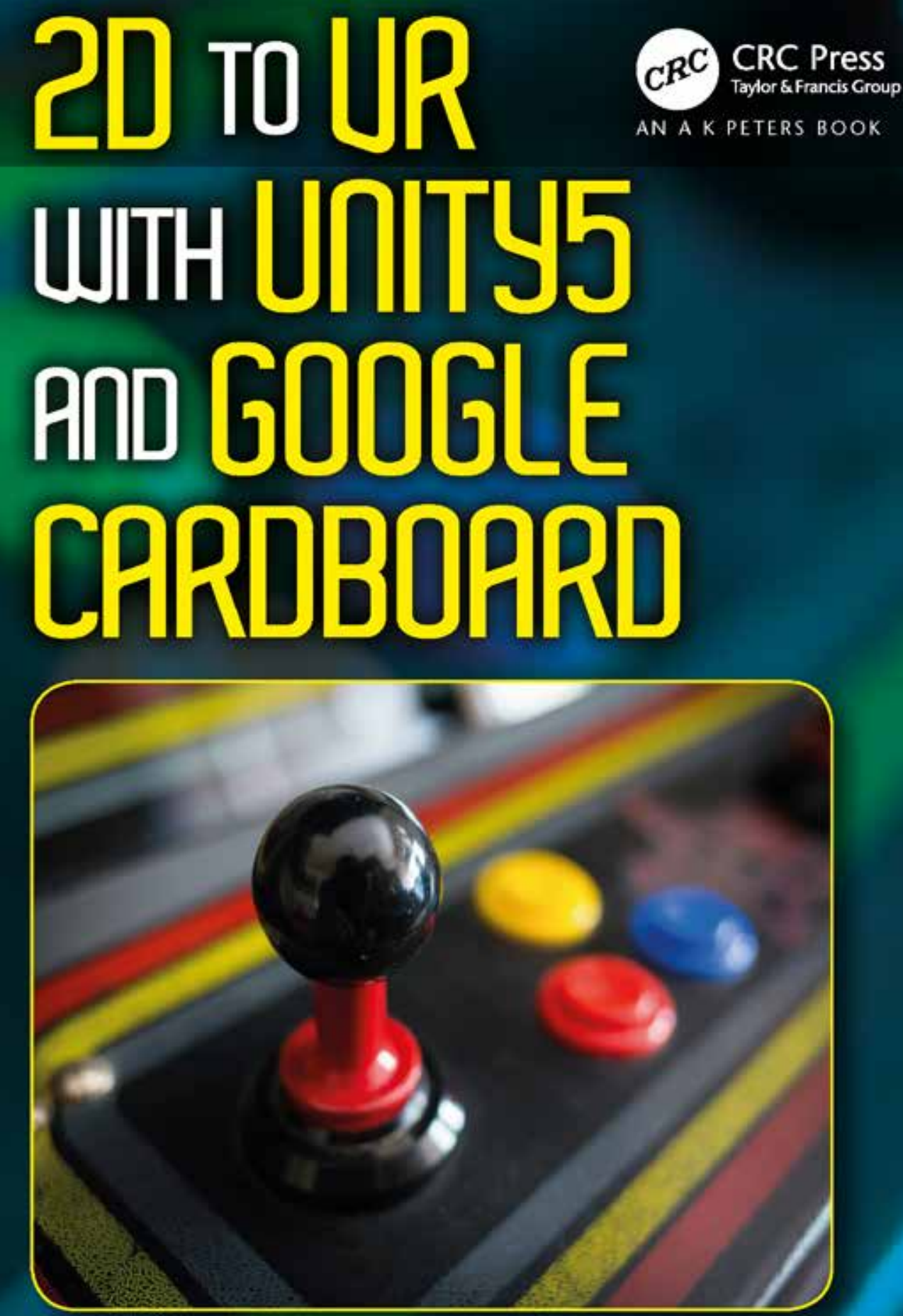

ROBERTODLLOก 
2D to VR with Unity5 and Google Cardboard 

Taylor \& Francis Group http://taylorandfrancis.com 


\title{
2D to VR with Unity5 and Google Cardboard
}

\author{
by \\ Roberto Dillon
}

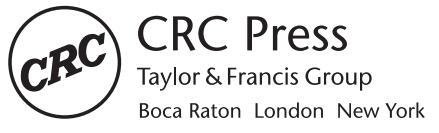

CRC Press is an imprint of the

Taylor \& Francis Group, an informa business

AN A K PETERS BOOK 


\section{CRC Press}

Taylor \& Francis Group

6000 Broken Sound Parkway NW, Suite 300

Boca Raton, FL 33487-2742

(C) 2017 by Taylor \& Francis Group, LLC

CRC Press is an imprint of Taylor \& Francis Group, an Informa business

No claim to original U.S. Government works

Printed on acid-free paper

International Standard Book Number-13: 978-1-4987-8152-7 (paperback)

978-1-138-62886-1 (hardback)

This book contains information obtained from authentic and highly regarded sources. Reasonable efforts have been made to publish reliable data and information, but the author and publisher cannot assume responsibility for the validity of all materials or the consequences of their use. The authors and publishers have attempted to trace the copyright holders of all material reproduced in this publication and apologize to copyright holders if permission to publish in this form has not been obtained. If any copyright material has not been acknowledged please write and let us know so we may rectify in any future reprint.

Except as permitted under U.S. Copyright Law, no part of this book may be reprinted, reproduced, transmitted, or utilized in any form by any electronic, mechanical, or other means, now known or hereafter invented, including photocopying, microfilming, and recording, or in any information storage or retrieval system, without written permission from the publishers.

For permission to photocopy or use material electronically from this work, please access www.copyright.com (http://www.copyright.com/) or contact the Copyright Clearance Center, Inc. (CCC), 222 Rosewood Drive, Danvers, MA 01923, 978-750-8400. CCC is a not-for-profit organization that provides licenses and registration for a variety of users. For organizations that have been granted a photocopy license by the CCC, a separate system of payment has been arranged.

Trademark Notice: Product or corporate names may be trademarks or registered trademarks, and are used only for identification and explanation without intent to infringe.

\section{Library of Congress Cataloging-in-Publication Data}

Names: Dillon, Roberto, author.

Title: 2D to VR with Unity5 and Google Cardboard / Roberto Dillon.

Description: Boca Raton : Taylor \& Francis, CRC Press, [2017]

Identifiers: LCCN 2016035592 | ISBN 9781498781527 (pbk. : alk. paper)

Subjects: LCSH: Computer games--Programming. | Unity (Electronic resource) |

Video games--Design. | Three-dimensional display systems. | Virtual

reality. | Google Cardboard (Three-dimensional display system)

Classification: LCC QA76.76.C672 D5338 2017 | DDC 794.8/1526--dc23

LC record available at https://lccn.loc.gov/2016035592

Visit the Taylor \& Francis Web site at

http://www.taylorandfrancis.com

and the CRC Press Web site at

http://www.crcpress.com 
To Marina (1973-2007) and Davide (1973-2016) 

Taylor \& Francis Group http://taylorandfrancis.com 


\section{Contents}

Foreword, ix

Introduction, $\mathrm{xi}$

Acknowledgments, xiii

Author, xv

Section I Our First Game

ChAPTER 1 - Getting Around in Unity 3

ChAPTER 2 - Setting Up a Platform Game 13

CHAPTER 3 - Running and Jumping 33

ChAPTER 4 - Sound and More

53

ChAPTER 5 - Scoring and Final Touches

65

SeCtION II Building a Match 3 Game for PC and Mobile

Chapter 6 - Game and Music Managers

79

ChAPTER 7 . "Jem Matcher:" Part 1

EXERCISE 1

$\begin{array}{ll}\text { EXERCISE } 2 & 120\end{array}$

CHAPTER 8 - "Jem Matcher:" Part $2 \quad 121$

EXERCISE 130 
ChAPTER 9 - Moving to Mobile 131

EXERCISE

SECTION III Developing a 3D Game for PC and VR

ChaPTER 10 - Terrain and First Person Character 141

ChaPter 11 - Enemies and Path Finding 157

ChAPTER 12 - Introduction to VR and Google Cardboard 177

ChaPter 13 - Porting to VR 189

SECtION IV Advanced Topics

\begin{tabular}{lr} 
CHAPTER 14 - Physics & 205 \\
\hline NEWTON'S FIRST LAW & 205
\end{tabular}

NEWTON'S SECOND LAW 209

Simulating Gravity 211

NEWTON'S THIRD LAW 212

EXERCISES 218

ChAPTER 15 - Introduction to Shaders 221

ChAPTER 16 - Setting up Unity Ads, IAPs, and Analytics 235

INDEX, 247 


\section{Foreword}

T WAS PROBABLY IN PRIMARY SCHOOL WHEN I STARTED dreaming about making games. In my head, games where made of ideas spawned from the imagination of the game designer, ideas that would be magically implemented in the software by the programming team. I wanted to be a game designer, and I thought programming was not something I had to dabble with.

Later on I found out that entering the game industry as a game designer was quite complicated because of the typical "Catch-22 dilemma:" nobody hires a designer without prior experience in the industry, but at the same time it's impossible to get industry experience without being in the industry in the first place. For somebody who couldn't afford to come out of a game design school, this was quite the problem.

My first foray into real game-making was using Adobe Flash around 2007. For the first time, Flash was allowing me to be the game designer, programmer, and even graphic artist, bridging the gap between my ideas and making them a reality that thousands of people could actually try.

The way games are made today is wildly different and this is true mostly thanks to the incredible pieces of software we have available. In time, game engines like Unity, Unreal Engine, Game Maker, Stencyl, Construct (and many others) had expanded on what Flash enabled in the first place, becoming a necessary tool to cope with the ever-changing landscape of platforms, consoles, technologies, and requirements. After Flash, in 2012 I chose Unity as my engine of choice for its flexibility and ease of use, and the huge community and amount of online resources and books available to learn.

I now work at Unity Technologies, and I am amazed every day by how fast the panorama changes and how quickly the company-and thus, the engine-reacts to it. New stores coming out everyday, new platforms, $\mathrm{VR}$, rendering technologies, new controllers, new ways to monetize, a 
thousand different devices to support: being able to leave all these technical issues to the engine and focus on the gameplay is the biggest advantage we have over developers making games ten years ago.

With the power of these tools and several excellent didactical resources like the present book written by Roberto Dillon at your disposal, there's no excuse or strange industry Catch-22 to hold you off anymore. You have the potential to create something worthy, something inspiring, or-why not-the next masterpiece game.

Ciro Continisio

Technical Evangelist, Unity Technologies 


\section{Introduction}

E VERY DAY SPENT IN THE WORLD OF GAME development seems more exciting than the previous one: new games, new technologies, and groundbreaking ideas seem to pop out of nowhere and amaze us in ways that were thought to be impossible not long ago. This technological revolution we live in was also made possible by the constant "democratization" of development that, thanks to state-of-the-art tools like the Unity game engine, has allowed many people to shape their ideas and create new and astonishing software with relative ease.

Unity itself is in constant evolution: new features are added by a very talented group of engineers, updates follow each other on a tight schedule, and plenty of good books covering different aspects of the engine are already available. Yet I felt there was still room for another volume that, like every good teacher should do, wouldn't try to teach "everything" that the engine offers today (including features that will doubtlessly become obsolete tomorrow), but would instead impart a thoughtful and sound knowledge enabling students to build a solid foundation upon which they will later be able to expand in the areas they are most interested inwhether mobile development, 2D games, or virtual reality (VR)-while staying up to date with the latest features.

To achieve this, the book is structured into four parts that integrate and complement each other to provide a comprehensive overview of what Unity has to offer. In the first part, after a general introduction, a simple $2 \mathrm{D}$ game prototype is explained in detail, giving us the opportunity to get used to several of the engine's fundamental building blocks, like scripting and Mecanim. Part II expands on the first by building a simple match-3 game to be deployed also on mobile, and Part III, instead, moves into $3 \mathrm{D}$ by building a first-person game that will also be experienced in VR through the wildly popular and inexpensive Google Cardboard. 
The last part covers some additional topics that will help beginners in gaining a basic understanding of more advanced aspects of game development, like Physics and Shaders, besides offering an overview of the latest features added to Unity 5, like rewarded ads and in-app purchases, which are of fundamental importance to monetize modern mobile games. Example Unity packages based on the various chapters can be downloaded from the website http://ProgramAndPlay.com.

Finally, do note that, while this book is aimed at beginning Unity developers, a basic grasp of fundamental programming concepts, like variables, arrays, functions, classes, and so on, is assumed.

Enjoy your journey as a game developer with Unity: remember, we never stop learning, so be curious about anything that happens inside, as well as outside, the Unity community.

I really hope to play some of your own games soon!

Roberto Dillon

Singapore, July 14, 2016 


\section{Acknowledgments}

Several people helped me during the writing of this book. I am Sespecially grateful to Ciro Continisio and Tony Peters for their feedback and help, my students, the whole Unity community, and, of course, my family for their constant support. Special thanks, also, to Rick Adams and Jessica Vega from CRC Press/Taylor \& Francis Group and Jennifer Brady from Deanta Global for turning this manuscript into a reality. 

Taylor \& Francis Group http://taylorandfrancis.com 


\section{Author}

Dr. Roberto Dillon is the author of several well-received game-related books published by AKPeters, CRC Press, and Springer, including On the Way to Fun, The Golden Age of Video Games, and HTML5 Game Development from the Ground-Up with Construct 2.

$\mathrm{He}$ is active both as an indie developer, through his Singapore-based studio, Adsumsoft, and as an academic in the field of game design and development. His games have been showcased at events like Sense of Wonder Night in Tokyo, FILE Games in Rio de Janeiro, and the Indie Prize Showcase at Casual Connect, besides reaching top positions on Apple's App Store and Google Play across several countries and categories.

He is currently an associate professor at James Cook University (JCU) in Townsville, Queensland, Australia, lecturing game design and project management classes. Before joining JCU, he was chair of the Game Software Design and Production Department at the DigiPen Institute of Technology, Singapore, teaching a variety of courses ranging from games history to game mechanics, with his students gaining top honors at competitions like the Independent Games Festival (IGF), both in San Francisco and Shanghai. 

Taylor \& Francis Group http://taylorandfrancis.com 


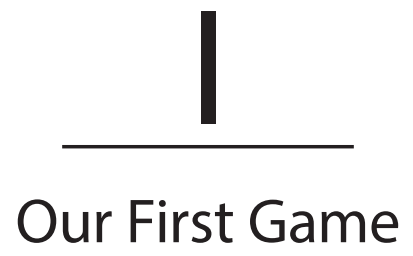



Taylor \& Francis Group http://taylorandfrancis.com 